\title{
LA RELACIÓN ENTRE EL ARTE VISUAL Y EL DISEÑO COMERCIAL DE BENETTON
}

\section{THE RELATION BETWEEN THE VISUAL ART AND THE BENETTON'S COMMERCIAL DESIGN}

\begin{abstract}
ARACELI SONI SOTO, DARÍO GONZÁLEZ GUTIÉRREZ

Universidad Autónoma Metropolitana, México

Araceli http://orcid.org/oooo-0003-4840-6547

Darío http://orcid.org/ oooo-0002-1114-980X

aracelisoni93@gmail.com
\end{abstract}

Recepción: 27 de agosto de 2020

Aprobación: 26 de octubre de 2020
RESUMEN

Este artículo se propone estudiar los vínculos entre los campos del arte visual y el diseño de la comunicación gráfica en las campañas comerciales de la marca Benetton, elaboradas por Oliverio Toscani entre los años 80 del siglo pasado y el año 2000. Con base en los entramados conceptuales de John B. Thompson y Pierre Bourdieu, utilizamos el método deductivo en esta investigación. Nuestros hallazgos muestran que las campañas se aproximan al arte en aspectos como la estética de lo feo; elementos realistas con imágenes desgarradoras; la recreación de problemas sociales. Ambos campos conservan su autonomía y construyen sus formas simbólicas de manera distinta. El valor del artículo reside en la exposición sobre un debate inacabado sobre los límites del arte visual y el diseño gráfico, disciplinas que inciden en el espacio social, y conforman nuestras ideas y formas de vida.

Palabras clave: campos de interacción, formas simbólicas, Oliviero Toscani
ABSTRACT

This paper has the purpose to study the links between the visual arts and graphic communication design fields in the Benetton's commercial campaigns, made by Oliviero Toscani between the eighties and the 2000 year. Based on the conceptual frameworks from John B. Thompson and Pierre Bourdieu, we use the deductive method in this research. Our finds show that these campaigns are closed to the arts in several aspects: the disgusting aesthetics, realistic elements with heartbreaking images, the recreation of social problems. Both fields keep their autonomy and made their symbolic forms in a different way. The value of this paper consists in the exposition of the unfinished debate about the limits of the visual arts and the graphic design, disciplines that influence the social space and shape our ideas and ways of life.

Keywords: interaction fields, Oliverio Toscani, symbolic forms 
ARTí́CULo

ARACELI SONI, DARÍO GONZÁLEZ GUTIÉRREZ

La relación entre el arte visual y el

diseño comercial de Benetton.
INTRODUCCIÓN

El siguiente escrito tiene la finalidad de esclarecer los límites entre el arte y el diseño comercial de la marca Benetton, en el contexto de la década de 1980 al 2000 . Oliverio Toscani fue el fotógrafo, publicista y diseñador de la empresa; su propuesta, novedosa y original, rompió algunos cánones de la publicidad convencional: sus estereotipos de belleza y muchos de sus símbolos; propuso motivos afines al arte, tanto por sus cualidades formales como por sus contenidos, que incluyeron problemas sociales como la discriminación racial y sexual, los estragos de la guerra y la migración, la violencia criminal y la pena de muerte, entre otros.

El tema es de importancia al propiciar un debate inacabado entre las fronteras del arte y el diseño, aunque este artículo se circunscriba, sobre todo, a la relación entre el arte visual y el diseño gráfico comercial. Es relevante, también, porque la publicidad en los medios de masas incurre en el espacio que nos circunda, conforma nuestras ideas, pensamientos, hábitos, costumbres, formas de vida y porque Toscani aporta pautas alternativas para un diseño comercial con impacto social.

De acuerdo con nuestro análisis e interpretación, este artículo contribuye a esclarecer los siguientes elementos del arte en las campañas de Benetton: a) una estética de lo desagradable y lo grotesco, similar a algunas producciones artísticas; b) elementos realistas con fotografías de hechos desgarradores del entorno social; y c) contenidos de problemas sociales de su contexto, aunque con fines comerciales. Toscani transgredió algunas reglas de la publicidad convencional, se acercó a concepciones estéticas y artísticas, suscitó polémicas en un sector acostumbrado a la belleza superficial de las Top Models y la felicidad banal, que impactaron, asombraron y generaron repulsión, sin embargo, su originalidad posicionó la marca entre los consumidores e incrementó sus ventas.

Con el método deductivo esclarecemos los límites precisos entre el arte visual y el diseño de la comunicación gráfica de Benetton; partimos del entramado teórico sobre las construcciones significativas que John Brookshire Thompson (2006), entendió como formas simbólicas, dentro de su concepción estructural de la cultura.' Por la importancia de la comprensión contextual de las formas simbólicas, recurrimos, también, al concepto campos de interacción de Pierre Bourdieu. Estos sistemas de ideas explican el papel de las campañas de Benetton en su contexto histórico y social. El estudio condujo a la comprobación de la siguiente hipótesis: a pesar de su ancestral interacción, los campos del

1 Para el autor, la concepción estructural de la cultura, no es una alternativa a la concepción simbólica, sino una modificación que considera los contextos y los procesos estructurados socialmente. El término "estructural" no debe confundirse con "estructuralista". Éste se usa, generalmente, para aludir a una variedad de métodos, ideas y doctrinas asociados con algunos pensadores franceses. Los métodos estructuralistas se relacionan con los rasgos internos de las formas simbólicas y la concepción estructural con los contextos y procesos estructurados socialmente (Thompson, 2006). 
ARTíCULO

ARACELI SONI, DARÍO GONZÁLEZ GUTIÉRREZ

La relación entre el arte visual y el diseño comercial de Benetton.

arte y el diseño conservan sus límites y su autonomía, al igual que sus formas simbólicas, sus especificidades.

La estructura del artículo consta de tres apartados: el primero esclarece los conceptos teóricos que delimitan las autonomías de los campos y sus formas simbólicas. En el segundo, se incursiona en la trayectoria del diseñador y artista Oliverio Toscani, sus propósitos y sus ideas en la concepción de sus campañas más sobresalientes del periodo. En el tercero, se analizan algunas formas simbólicas, a fin de observar su afinidad con el arte. Finalmente, se presentan las conclusiones.

\section{CONFLUENCIAS ENTRE EL ARTE Y EL DISEÑO COMERCIAL}

Los productos del arte y el diseño en cuanto objetos de significación cultural tienen diferencias irreductibles: sus intenciones, convenciones, estructuras y referencias responden a contextos y campos de interacción diferentes. Para esclarecer los rasgos del contexto, Thompson (2006) retoma de Pierre Bourdieu el concepto "campo de interacción", 2 quien lo concibe de manera sincrónica -espacio de posiciones-y diacrónica - conjunto de trayectorias-, ambas determinadas por la cantidad y el tipo de "capital". Esto es, los agentes ${ }^{3}$ situados en cierta posición, en un espacio social, siguen en sus vidas trayectorias determinadas por su capital económico, cultural, social o simbólico. ${ }^{4}$ La cultura incluye normas, costumbres y expresiones de un grupo social. Los campos son ámbitos especializados de la actividad humana: educativo, artístico, deportivo, estructurados de manera jerárquica. El conocimiento de sus convenciones y reglas predisponen el habitus ${ }^{5}$ del agente, es decir, conforma sus esquemas para actuar, pensar y sentir de acuerdo con su posición social, lo cual le permite interactuar con los otros en su campo (Bourdieu, 1996).

Los productos de diseño gráfico comercial y las obras de arte son productos culturales que se ubican en dos campos distintos, los primeros satisfacen necesidades comunicativas para la comercialización y los segundos, estéticas; en ambos casos su significado rebasa su representación objetiva: son expresiones significativas que Thompson (2006)

3 postura del estructuralismo, el cual considera que los sujetos están determinados por la estructura social a la que pertenecen, sin la autonomía ni la capacidad de incidir en ella.

4 El capital económico refiere a los bienes (incluido el cuerpo) y al dinero; el cultural a los conocimientos: la educación, la formación intelectual y la artística; el social comprende los contactos, las relaciones familiares, de asociación o de amistad. El simbólico es subjetivo, producto de la valoración de los otros agentes (Bourdieu, 1988 y 2011).

5 El habitus favorece el trazo de estrategias y su elección con una libertad acotada; es constitutivo de las clases sociales, sus agentes tienen condiciones de existencia homogéneas, condicionamientos, sistemas de disposiciones que generan prácticas y actuaciones semejantes en los miembros de la misma clase social (Bourdieu, 1988). 
ARTíCULO

ARACELI SONI, DARÍO GONZÁLEZ GUTIÉRREZ

La relación entre el arte visual y el diseño comercial de Benetton. denomina "formas simbólicas", 6 al igual que los productos cinematográficos, de televisión, las ceremonias religiosas, los gestos, algunas acciones y toda construcción cultura. Tanto su producción como su recepción dependen de las intenciones y del lugar que los agentes ocupan en su campo. Quien adquiere una obra de arte obtiene un capital económico y cultural que refuerza su pertenencia al campo y lo distingue de los demás, con lo cual aumenta su reputación y su capital simbólico (Bourdieu, 2011). Algo similar sucede con las mercancías respaldadas en el diseño, por ejemplo, la ropa de marca, pues da prestigio y afirma la posición del comprador.?

Los agentes de diferentes campos interactúan entre sí, tal y como lo muestra la historia del arte y el diseño. Desde la segunda mitad del XV, gracias al desarrollo de la imprenta, en Alemania se realizan libros ilustrados con la colaboración de impresores, grabadores, ilustradores y pintores (Meggs, 2010). Siglos después, a mediados del XIX, en París muchos artistas influidos por los movimientos modernistas emplearon el lenguaje poético de la pintura para elaborar carteles de productos de consumo cotidiano y de espectáculos en la ciudad (Barnicoat, 2003; Rubin, 2006). En el siglo XX, corrientes como el Op Art, el Pop Art, el Surrealismo, constatan sus vínculos: utilizan imágenes, colores y signos afines al diseño. Quizá por esto el público, durante años, no distinguió sus diferencias: en los años sesenta a los diseñadores de la comunicación gráfica se les solicitaban productos originales con gran creatividad y rasgos artísticos (Zimmermann, 2005). Después de la Primera Guerra Mundial se fundó la Bauhaus en Weimar, primera escuela para la enseñanza del diseño en varias modalidades: arquitectura, diseño industrial, gráfico, textil. Su fundador, Walter Gropius, incorporó a destacados artistas ${ }^{8}$ y logró la afortunada conjunción entre diseño y arte que fructificó en objetos funcionales, con formas atractivas, al servicio de la sociedad.

Si tomamos en cuenta los aspectos que distinguen a las formas simbólicas del arte y el diseño, se explica tanto la autonomía como la interacción entre estos campos. Debido a su variedad, nos enfocamos al diseño gráfico comercial y las artes visuales de acuerdo con las características enunciadas por Thompson:

a. su intencionalidad: los artistas expresan sus contenidos y emociones con mayor libertad; los diseñadores satisfacen necesidades prácticas y tienen objetivos precisos para comunicar e incidir en la conducta del receptor.

6 Para Thompson (2006) las formas simbólicas son construcciones significativas interpretadas y comprendidas por los individuos que las producen y las reciben; a la vez se estructuran de maneras diferentes y se insertan en condiciones sociales e históricas específicas.

7 El capital es una relación social que existe sólo en el campo en que se produce (Bourdieu, 1988), por lo cual el capital simbólico que obtiene un consumidor de arte, se lo otorgarán los miembros de su mismo campo.

8 Como Johannes Itten, Lyonel Feininger, Gerhard Marcks, Georg Muche, Wassily Kandinsky, Laszlo Moholy-Nagy, Oskar Schlemmer, Paul Klee, Lothar Schreyer, entre otros (Wick, 2007). 
ARTíCULO

ARACELI SONI, DARÍO GONZÁLEZ GUTIÉRREZ

La relación entre el arte visual y el diseño comercial de Benetton. b. su convencionalidad: los signos artísticos son menos cerrados que los del diseño, tienen mayor afinidad con los símbolos, lo que conduce a que sus significados sean más ambiguos, aunque depende del tipo de arte, de la corriente y del estilo propio del artista. El arte tiene como fin el disfrute, aun cuando el público, desconozca sus significados precisos. El diseño emplea signos acordados a fin de cumplir con su objetivo: la transmisión de mensajes que influyen en las acciones del público; en el caso del diseño de objetos de uso, estos deben comunicar su función.

c. su estructura: las disciplinas artísticas obedecen a reglas propias de composición, cuyos elementos se articulan en un todo que generará efectos estéticos en los receptores; el diseño tiene las propias y la interrelación entre sus componentes sigue, también, ciertos principios para lograr la claridad de los mensajes.

d. su referencialidad: los referentes artísticos pueden ser reales, abstractos o imaginados, reflejan elementos del entorno social, cultural y artístico. El diseño comercial refiere a los productos que promociona y un objeto de uso es autorreferencial al representar su propia función, pues el usuario debe entender cómo utilizarlo.

e. su contexto: la obra de arte se crea y se recibe en tiempos y espacios particulares que pueden variar según sea el caso — talleres, museos, salas de lectura, etcétera-. El de los mensajes de diseño gráfico comercial se inscribe en los medios electrónicos, en los soportes digitales e impresos. El contexto de un objeto de uso remite a los comercios, la casa, entre muchos otros.

A pesar de las relaciones entre los campos del arte y el diseño a través de la historia, las observaciones anteriores evidencian las diferencias entre sus formas simbólicas. El primero es un vehículo de expresión libre del artista, crea universos estéticos y sensibles para el enriquecimiento del espíritu, mientras el diseño gráfico comercial responde a requerimientos precisos de comunicación y persuasión, para lo cual recurre a fórmulas y a estereotipos que inducen al consumo de bienes y servicios. Por su carácter expresivo el arte recurre a símbolos abiertos a la libre interpretación, ${ }^{9}$ mientras el diseño gráfico comercial utiliza códigos cerrados, ampliamente convenidos, que le ayudan a cumplir con su cometido: que el público conozca y consuma los productos que difunde. De ahí que una de las características del arte, sea la ambigüedad. En este sentido, tanto el arte como el diseño gráfico publicitario tienen su propio atractivo que los distingue y los relaciona, tanto en sus contenidos como en la forma de representar los fenómenos, como lo veremos en el análisis del diseño gráfico comercial de Benetton.

9 Al referirse al arte contemporáneo, en los años sesenta Umberto Eco (1992) aludió a la apertura planteada en la composición de la obra que favorece la autonomía interpretativa de acuerdo con la sensibilidad y competencias del receptor. 
ARTíCULO

ARACELI SONI, DARÍO GONZÁLEZ GUTIÉRREZ

La relación entre el arte visual y el diseño comercial de Benetton.

\section{LAS CAMPAÑAS DE TOSCANI PARA LA COMERCIALIZACIÓN DE BENETTON}

La publicidad de Benetton, entre finales de los años 80 del siglo pasado y el año 2000 , fue polémica y llamativa; su realizador, Oliverio Toscani, adquirió su formación artística en la Escuela de Artes Aplicadas de Zúrich —dirigida por Johanes Itten- ${ }^{10}$ lo cual se reflejó en sus diseños comerciales. Desde 1965, Toscani elaboró reportajes sobre el ambiente del rock y fotografías publicitarias en revistas de moda italianas como Donna, Moda, Vogue, así como para la francesa Elle. En 1978 comienza a trabajar para la empresa de ropa Esprit en San Francisco, Estados Unidos, donde rediseña el logotipo, los catálogos y la publicidad; lanza la campaña "The Real People"." En esta etapa también trabajó para Elio Fiorucci quien, en 1982, lo presentó con Luciano Benetton (Toscani, 1996). Luciano, director de Benetton, busca una estrategia de publicidad original; contrató a Toscani y emprendió algunas acciones, como la creación de un departamento de publicidad al interior de su empresa. A finales de la década de los 80 compite, en el mundo, contra poderosas firmas, como Esprit y Jordache, sin gastos superiores al $4 \%$ del volumen de ventas. Benetton prescindió de medios caros, como la televisión o la radio, en cambio, utilizó carteles urbanos, inserciones en revistas populares y su propio equipo de Fórmula 1 (Mantle, 2000). Para obtener el máximo rendimiento con bajos recursos, Toscani ideó campañas provocativas que transgredieron los cánones del diseño comercial.

El primer cartel subversivo fue el de una mujer negra amamantando a un bebé blanco -campaña otoño-invierno en 1989-, con el que dio un nuevo sentido al emblema "United Colors": relacionó la combinación de los colores de la ropa con los de la piel para representar la unión fraternal entre etnias distintas (Salvemini, 2002: 45). Toscani describe el efecto de esta campaña con las siguientes palabras:

Sirvió como trampolín para desarrollar un estado de opinión antirracista, cosmopolita, antitabú, hasta incluso en países particularmente expuestos al racismo como Sudáfrica y Estados Unidos; transformó un eslogan publicitario en una gestión humanitaria. 'Coloreé' Benetton de una actitud progresista. La campaña desarrolló una imagen de marca, filosófica, y que iba más allá del mero consumo (Toscani, 1996: 48).

Pero hubo sectores a los que disgustó esta campaña y generaron un escándalo mediático que se difundió de manera expansiva; las críticas terminaron por promocionar la marca. Toscani creó una campaña original, de bajo costo y con gran impacto; con ella estableció

10 Profesor de la Bauhaus de 1919 a 1923.

11 Respecto a esta campaña, Toscani (1996: 125) dice que el propietario de Sprit, Doug Tompkins "comprendió en seguida que el valor real de un producto residía en su capacidad de comunicar". Y añade que esto también lo entendieron muchas empresas japonesas, como Seibu. 
ARTí́CULO

ARACELI SONI, DARÍO GONZÁLEZ GUTIÉRREZ

La relación entre el arte visual y el

diseño comercial de Benetton. una contrapropuesta a la publicidad convencional, la que criticó de forma mordaz. ¿Qué significa la foto de la mujer negra con un niño blanco en brazos? El fotógrafo quiso representar la armonía étnica como estrategia para incluir más consumidores, ${ }^{12}$ no obstante, para algunas asociaciones afroamericanas tenía una connotación racista, al mostrar a una nodriza negra al cuidado de un bebé de colonialistas blancos (Argante y Toscani, 2008).

¿Qué quiso decir el trasero con el sello H.I.V. positivo? Benetton exhibió estos carteles en 1993, como una contribución a la campaña contra el SIDA y así se consideró por muchas asociaciones; sin embargo, no faltaron protestas de grupos que opinaron lo contrario: se trataba de publicidad que promovía la discriminación contra los enfermos; incluso, boicotearon la marca. La ambigüedad de los carteles mencionados es, según se explicó, una característica del arte y uno de los aspectos, en los cuales se observa la confluencia entre las formas simbólicas del arte y el diseño. Este mismo rasgo se encuentra en "la campaña sobre los sexos de todas las edades y de todos los colores" de 1993 (Toscani, 1996: 97), cuya imagen tiene como base un cartel con fotografías en serie de genitales masculinos y femeninos; sus referencias en torno a la sexualidad son evidentes; con ello Toscani se propone lanzar un cuestionamiento sobre la identidad, al preguntarse "si podemos ser reconocidos con la sola contemplación de nuestro sexo, como de nuestro rostro" (Toscani, 1996: 98). El cartel fue censurado por toda Europa, aunque el periódico francés Libération lo publicó en página doble e hizo una venta récord.

Toscani adopta para sus campañas publicitarias la estética de lo feo y lo grotesco, tal y como se observa en una fotografía para la campaña otoño-invierno de 1991: un recién nacido ensangrentado aún con el cordón umbilical, cuya representación es completamente opuesta a la imagen idílica de la publicidad convencional con bebés de pieles blancas y tersas, con caritas sonrientes y cuerpos completamente limpios. El cordón umbilical es el último nexo con la madre, dadora de vida; el cuerpo ensangrentado recuerda el parto doloroso, evoca que la vida dista mucho de ser placentera; es dura y trágica, como la representan muchas creaciones artísticas cuya estética recrea lo feo, lo grotesco y lo desagradable. ¿Es esto lo que intentan borrar los cuerpos impecables de la publicidad? ¿Consumir los productos que promueve la propaganda comercial nos libera de estos males? Más bien, nos promete ideas irrealizables que evaden la abrumadora vida cotidiana y sus tragedias.

La fotografía realista de un seropositivo rodeado por su familia antes de morir — de la campaña primavera-verano de 1992- es contraria a las imágenes saludables y vitales de empresas como Coca-Cola, cuyos lemas venden felicidad: "el sabor de la vida", "la sensación

12 Igor Zabel (2012) muestra que la campaña "United Colors" coincide con la estrategia multiculturalista de los poderes globales que tiene dos vertientes a) la descrita por Rasheed Araeen que consiste en ocultar las contradicciones de la sociedad blanca y "entizar" a la población de otras culturas, y b) la estudiada por Slavoj Žižek: el multiculturalismo como "la forma ideal del capitalismo global" que, sin un centro definido, trata a todas las naciones como lugares a ser colonizados mientras oculta los intereses imperiales de los países del Norte. 
ARTíCULO

ARACELI SONI, DARÍO GONZÁLEZ GUTIÉRREZ

La relación entre el arte visual y el diseño comercial de Benetton. de vivir", "vive la vida", "el lado Coca-Cola de la vida", "la chispa de la vida”, "desde 1886 repartiendo felicidad", "destapa la felicidad”. Con la foto del moribundo, Toscani rompió con mitos sobre el SIDA, tales como el contagio a través del contacto y muestra que estos enfermos pueden convivir, tocarse y abrazarse con sus seres queridos hasta su último suspiro; nos recuerda, también, que la muerte es parte de la vida, que nadie escapará a ella, aun con el consumo de maravillosos productos.

Casi cincuenta años después del término de la Segunda Guerra Mundial se creyó que el continente europeo vivía en paz, sin embargo, la campaña "El soldado conocido", para primavera-verano de 1994, evoca que el mundo no ha conocido la tranquilidad y que la guerra forma parte del proceso civilizatorio. La fotografía del uniforme de Marinko Gagro —-soldado bosnio muerto en el conflicto armado de la antigua Yugoslavia - exhibe que los fallecidos en la guerra no son anónimos, sino seres de carne y hueso con nombre y apellido. ${ }^{13}$ Los edulcorados anuncios comerciales no representan la guerra y sus tragedias, la codicia, el poder y el sadismo de quienes disfrutan con la violencia y el sufrimiento ajeno. Este tipo de situaciones no se asocia a la adquisición de productos, solo puede ser representada por una estética realista y de lo feo, lo malo y lo trágico, en cuanto cualidades afines al arte.

Como en otras ocasiones, se acusó a Benetton de lucrar con el dolor ajeno, pero Toscani replicó en diversos medios. En su libro La publicidad es una carroña que nos sonríe, ${ }^{14}$ escribe que la publicidad "[...] se ha quedado en el estadio infantil del arte y del culto ingenuo a la belleza" (Toscani, 1996: 149), ya que el verdadero arte moderno no cree en mundos "aparentes", belleza superficial y felicidad banal, sino en la complejidad de la realidad misma, en la que también cabe la fealdad, la maldad y la tragedia. Toscani plasmó sus ideas en diversas imágenes y le dio una nueva dimensión a la publicidad, en la que conjugó lo comercial con la estética de lo feo y la función social respecto a los problemas más acuciantes del mundo contemporáneo. Las controversias de sus campañas bajaron de intensidad a fines de los años noventa, entonces se inspira en la obra de Andy Warhol sobre la muerte y realiza su serie publicitaria más polémica: la de la pena de muerte. Esta causó mucho disgusto en los Estados Unidos y algunas empresas, como Sears y boicotearon la marca; la polémica produjo su rompimiento definitivo con Luciano Benetton (Argante y Toscani, 2008; Salvemini, 2002).

\section{LAS IMÁGENES DE TOSCANI COMO FORMAS SIMBÓLICAS}

Toscani se inspiró en obras de arte para la concepción de sus campañas publicitarias, no obstante, la autonomía de estos campos y las diferencias entre sus formas simbólicas. El

13 Aunque más tarde se supo que el uniforme no era de este soldado.

14 La pub est une charogne qui nous sourit es el título original publicado en 1995. Fue traducido al castellano como Adiós a la publicidad. 
ARTíCULO

ARACELI SONI, DARÍO GONZÁLEZ GUTIÉRREZ

La relación entre el arte visual y el diseño comercial de Benetton. campo del diseño comercial de las campañas analizadas comprende el de los medios de masas, en especial el de las revistas impresas, el de los espectaculares en las ciudades e incide en el del deporte por el equipo de Fórmula 1 de Benetton. En este último el diseño del logotipo llegó a los aficionados de las carreras automovilísticas y reforzó el nombre de la marca, cuyos contextos fueron los autódromos. Al interior de esos espacios de acción o campos confluyen una red de relaciones conforme a las posiciones de poder y capital de sus agentes, bajo el amparo de instituciones gubernamentales y privadas de las comunicaciones, el urbanismo y el deporte. El contexto de los mensajes diseñados se extiende a las mercancías que incluyen su etiqueta o logotipo, a las tiendas donde se venden y a los centros comerciales.

El campo del arte, en cambio, se inscribe en una red de relaciones artísticas y culturales, se regula por instituciones distintas y se difunde en otros espacios y medios: museos, galerías, casas de cultura, escuelas, libros de arte. Puede haber coincidencias, por ejemplo, en el espacio urbano se exponen carteles publicitarios y obras de arte, así como en algunas galerías de centros comerciales se vende arte. Estas situaciones, sin embargo, tienen que ver con la comercialización del arte, momento en el que esas formas simbólicas se constituyen en mercancías al margen de sus rasgos artísticos. Asimismo, debido a la originalidad y al reconocimiento artístico de las obras publicitarias de Toscani, ${ }^{15}$ se expusieron en el Museo de Arte Contemporáneo de Lausana (1993), la Bienal de Venecia (1993), el Museo de Arte Moderno de México (1995), el Museo de Arte Moderno de Frankfurt y en São Paulo, Brasil (Mantle, 2000; Toscani, 1996); lo cual no hace más que constatar la cercanía entre los dos campos de interacción.

Es indudable que las campañas de Toscani corresponden al diseño comercial, aunque se concibieron de manera excepcional e "inteligente”, principal distintivo de la buena publicidad. Umberto Eco (2008), piensa que un buen anuncio tiene "ambiciones estéticas," cuya originalidad provoca reacciones favorables en el receptor, quien reconoce su "genialidad" y la traslada al producto, pensando que es "inteligente y de prestigio". Estos efectos se lograron en las campañas de Toscani, pues a pesar de las controversias suscitadas afianzó el prestigio de la marca, la posicionó en el mercado e incrementó sus ventas

El cartel de la mujer negra amamantando a un bebé blanco con la intención de promover la ropa Benetton e incidir en la conducta del público para comprarla, se concibe de manera poco convencional: la fotografía en el soporte de un anuncio pudiera mostrar explícitamente el producto, sin embargo, lo exhibe como elemento accesorio. La referencia directa de una imagen comercial es el producto, el suéter rojo, junto al logotipo de Benetton. Esto pasa a segundo plano y el principal referente es la armonía étnica entre europeos y africanos. En la estructura de la fotografía destacan los colores, que conducen al lema

15 Las campañas y mensajes publicitarios tienen una vida efímera; cuando caducan y salen del circuito mercantil pueden ser reconocidos sus valores artísticos (Moles y Costa, 2005). 
ARTíCULO

ARACELI SONI, DARÍO GONZÁLEZ GUTIÉRREZ

La relación entre el arte visual y el

diseño comercial de Benetton. de la campaña "United Colors": el rojo del suéter abierto enmarca la imagen por ambos lados y contrasta con las pieles negra y blanca de los modelos. La composición rompe con lo acostumbrado: por el motivo, por la forma en que se presenta el torso desnudo y porque la cara de la mujer aparece cortada. El contexto lo determinan los lugares en que se localizaron los soportes publicitarios — principalmente Europa y Estados Unidos-y la temporalidad de su exposición: el año 1989. Cuando cae el muro de Berlín se derrumba el paradigma del "socialismo real", el neoliberalismo se expande y las grandes empresas conquistan nuevos mercados. La multinacional Benetton incluye en su publicidad un nuevo tipo étnico - la mujer africana - como estrategia para ganar consumidores. ${ }^{16}$ Estas características no corresponden a las de una obra artística, cuya intención es la expresión libre del creador, sino la de dar a conocer el producto para su compra, mientras que el artista crea su estilo, su propio lenguaje, su idiolecto y para comprender su obra es necesario compenetrarse con un conjunto de aspectos, tales como saber quién es el artista, conocer su contexto, su corriente, sus influencias, sus lecturas; en los anuncios de Benetton el público debe entender que se promueve una marca de ropa. La originalidad de este diseño comercial impacta, sorprende, desconcierta a primera vista, pero al observar el logotipo se descifra la intención del mensaje, ya que este es el sello que le da identidad a la marca: dirige su significación, inhibe que el sentido de las imágenes se disperse y se aparte de su intencionalidad. A excepción de este elemento, que ocupa un mínimo espacio en el diseño de los carteles, lo que sobresale son fotografías, de gran tamaño, impactantes, ambiguas, en tanto que carecen de lemas y textos que apoyen la significación de la imagen, o sea, se abren a la interpretación. ${ }^{17}$ Por sus referentes ambiguos, simbólicos y su estructura, el anuncio de la mujer africana amamantando al bebé podría calificarse como una fotografía artística. Salvemini (2002) la compara con un detalle de La tempestad, pintura de Giorgione (ca. 1508). Sin embargo, el logotipo anclado en el cartel, permite identificarlo como un producto del diseño comercial, cuyo fin responde a los intereses económicos de la empresa Benetton. Aunque el lugar de exhibición de una obra de arte y de los anuncios de Benetton podrían coincidir, como sucede con las piezas conceptuales de algunos anuncios espectaculares o las que se venden en centros comerciales, la mayor parte de las obras artísticas, como se explicó, tienen otros espacios de exhibición.

A pesar de su afinidad con obras artísticas de la estética de lo feo, la intencionalidad de la fotografía del recién nacido ensangrentado es meramente comercial, aun cuando Toscani sea original al asociar esta imagen con la ropa Benetton de manera "inteligente"

16 Ver nota 12.

17 Dentro de los tres tipos de mensaje publicitarios se encuentra el lingüístico. Puede desempeñarse de dos maneras: como relevo en caso de complementar el sentido de las imágenes en secuencia; de anclaje, para evitar la dispersión significativa de la imagen fija. Este último precisa la significación y evita que los espectadores relacionen el mensaje con códigos ajenos a la intencionalidad publicitaria (Barthes, 1986). 
ARTíCULO

ARACELI SONI, DARÍO GONZÁLEZ GUTIÉRREZ

La relación entre el arte visual y el diseño comercial de Benetton. y enfatizando su "prestigio". Por esta razón, el anuncio no sigue las convenciones de la publicidad, su referente, el recién nacido y el personal médico de la imagen no tienen que ver con la marca en el logotipo; éste aparece marginalmente. La estructura fotográfica denota una buena composición: un trazo en diagonal —determinado por la posición del recién nacido- remata a la derecha con los médicos. Los contextos de tiempo y espacio en la exhibición del cartel son similares a los descritos anteriormente, propios de la propaganda comercial, aunque, ocupados en ocasiones, por el arte conceptual.

Lo mismo sucede con la imagen del enfermo de SIDA: sus afinidades con la estética de lo feo no inciden en su intencionalidad comercial; sus convenciones no son las de la publicidad tradicional; su referente no remite a Benetton más que por el logotipo; su estructura - compuesta por cuatro personas en torno al moribundo- está bien lograda, aunque la fotografía no es de Toscani, sino de Thérèse Frare. Salvemini (2002) también la compara con una obra artística, El entierro de Cristo, de Caravaggio (ca. 1604).

La campaña sobre la pena de muerte, la más polémica de todas, también devela una inspiración artística; el tema lo trabajó Andy Warhol desde 1962, con varias obras sobre la muerte, entre ellas 129 muertos en un avión, El hombre más buscado - una serie de fotografías de rostros de fugitivos, con sus nombres y el número de registro policial- y varias piezas en las que incluye la silla eléctrica: Desastre lavanda, Doble desastre plateado, Gran silla eléctrica, entre otras (Díaz, 2009). Las imágenes de Toscani tienen una clara referencia a la serie El hombre más buscado, pues también tienen el nombre del criminal y algunos datos de la ficha policiaca (Salvemini, 2002). Nuevamente el logotipo es referente de la imagen, ancla la marca, determina su intencionalidad y sus demás características como forma simbólica comercial.

\section{CONCLUSIONES}

El diseño comercial de Benetton recurrió a imágenes impactantes sobre los problemas sociales de finales del siglo XX; su originalidad se homologó con la de los productos de la marca y les confirió la “inteligencia” referida por Eco; propiedad que también asumió el consumidor: quien compra una prenda de Benetton adquiere la cualidad de alguien "informado" o, por lo menos, interesado en los temas de actualidad como pueden ser la discriminación racial o sexual, los estragos de la guerra o la migración, la violencia criminal o la pena de muerte.

Los productos de esta firma se dirigen a la clase media con algunas aspiraciones intelectuales e intereses en los campos del arte y el diseño, lo cual se deduce a partir de las composiciones de los anuncios con motivos afines al arte, los medios en los que circulan, los colores y el diseño de las prendas, su costo, la ubicación de los puntos de venta. El poder adquisitivo de este público le permitió acceder a la compra de periódicos, de libros de 
ARTíCULO

ARACELI SONI, DARÍO GONZÁLEZ GUTIÉRREZ

La relación entre el arte visual y el diseño comercial de Benetton. arte, a museos y a otras actividades artísticas, lo cual lo acercó al reconocimiento de los temas reproducidos en imágenes.

La promoción de las prendas de Benetton, mediante el deporte automovilístico reforzó las ideas de originalidad e "inteligencia” aludida; esta fue la única marca de ropa cuyos propietarios poseían un equipo de Fórmula 1. Con esta estrategia Benetton amplió su número de clientes en este exclusivo sector.

Al incluir en sus imágenes modelos africanos, europeos y asiáticos para captar más consumidores, el enfoque multiculturalista de la campaña “United Colors” generó la idea respecto al interés de la empresa por las desigualdades étnicas. Esto, que se presentó como una acción democrática a favor de la fraternidad entre las etnias, coincidió con las estrategias de los poderes globales para ocultar las contradicciones del sistema económico y sus métodos de control y explotación. La pantalla multiculturalista promueve la armonía entre grupos humanos diversos, pero dentro del engranaje del capitalismo mundial que los dirige al consumo.

Las campañas otorgaron prestigio a los productos y, por ende, a sus compradores, quienes intercambiaron su capital económico por el simbólico, a través de la elección de mercancías valoradas por otros miembros de su clase social. El capital simbólico de los campos del arte, el diseño y el deporte combinados confirieron a los poseedores de las prendas Benetton la estimación y el afianzamiento de sus trayectorias al interior de una sociedad estratificada jerárquicamente, tal y como lo afirma Bourdieu.

Como se expuso, las formas simbólicas del diseño comercial de Benetton se acercaron al arte, sin embargo, prevaleció la intencionalidad mercantil. La ruptura de las convenciones publicitarias propició la ambigüedad de sus mensajes, no obstante que el anclaje de la marca dirigió el significado a su público e indujo su conducta hacia la adquisición de sus productos. Esto, gracias a que Benetton ya era una marca conocida, por lo cual la sola presencia del logotipo fue suficiente para que el público lo asociara con su prestigio previamente establecido, sin la necesidad de aportar información detallada de sus mercancías.

La relación de las campañas de Benetton con la estética de lo feo, con el arte contemporáneo, su estilo realista, así como las referencias a los problemas sociales y la disolución de las convenciones publicitarias otorgaron a Toscani el reconocimiento artístico de su trabajo: su obra se exhibió en varios museos una vez que terminó el ciclo de sus campañas publicitarias. Tal y como se expuso, los campos del arte y el diseño interactúan de manera constante, aun así, conservan su autonomía y sus especificidades. J 
ARTÍ́CULO

ARACELI SONI, DARÍO GONZÁLEZ GUTIÉRREZ

La relación entre el arte visual y el diseño comercial de Benetton.

\section{REFERENCIAS}

Argante, E. y O. Toscani (2008). Creativo Sovversivo. Roma: Editorial Salerno.

Barnicoat, J. (2003). Los carteles, su historia y su lenguaje. México: Editorial Gustavo Gili.

Barthes, R. (1986). Lo obvio y lo obtuso. Imágenes, gestos, voces. Barcelona: Editorial Paidós.

Bourdieu, P. (1988). La distinción. Criterios y bases sociales del gusto. Madrid: Editorial Taurus.

Bourdieu, P. (1996). Cosas dichas. Barcelona: Editorial Gedisa.

Bourdieu, P. (2011). Las estrategias de la reproducción social. México y Buenos Aires: Editorial Siglo XXI.

Díaz, M. (2009). Andy Warhol. Madrid: Editorial Tikal.

Eco, U. (1992). Obra abierta. Barcelona: Editorial Planeta-Agostini.

Eco, U. (2008). La struttura assente. Milán: Editorial Bompiani.

Mantle J. (2000). Benetton. The family, the Business and the Brand. Londres: Editorial Warner.

Meggs, P. B. (2010). Historia del diseño gráfico. México: Editorial Trillas.

Moles, A. y J. Costa (2005). Publicidad y diseño. El nuevo reto de la comunicación. Buenos Aires: Editorial Infinito.

Rubin, J. H. (2006). Impressionism. Londres: Editorial Phaidon.

Salvemini, L. P. (2002). United Colors. The Benetton Campaigns. Londres: Editorial Scriptum.

Thompson, J. B. (2006). Ideología y cultura moderna. Teoría crítica social en la era de la comunicación de masas. México: UAM-X.

Toscani, O. (1996). Adiós a la publicidad. Barcelona: Editorial Omega.

Wick, R. (2007). Pedagogía de la Bauhaus. Madrid: Editorial Alianza.

Zabel, I. (2012). Contemporary Art Theory. Zúrich, Dijon: Editorial JRP Ringier y Les presses du réel. Zimmermann, Y. (2005). “El arte es arte, el diseño es diseño”. En Anna Calavera (ed.). Arte ¿? Diseño. Nuevos capítulos en una polémica que viene de lejos. Barcelona: Editorial Gustavo Gili. 